\title{
ГЕРОИ И АНТИГЕРОИ ПРОИЗВОДСТВЕННОГО РОМАНА (НА ПРИМЕРЕ РОМАНА «СОТЬ» Л. ЛЕОНОВА)
}

\author{
Московский педагогический государственный университет, г. Москва, Россия
}

Аннотация. В статье рассмотрены персонажи произведения «Соть» Л. Леонова, которое советская критика относила к жанру производственного романа. Авторы анализируют систему персонажей и выдвигают гипотезу, соответствующую жанровому канону производственного романа о воспитании личности. В процессе анализа текста обнаруживается, что жанровые установки типичного производственного романа в «Соти» не реализованы и он расширяет рамки жанрового канона. Строительство бумажного комбината на реке Соть разделило людей на два враждующих лагеря - сторонников и противников индустриализации крестьянской глубинки. Предприятие, которое главный герой И. Увадьев считает «фабрикой по производству новых людей» из «человеческой глины», в реальности становится доминантой топоса их «сортировки», а не перевоспитания. Строительство комбината как «моста в будущее» для И. Увадьева и С. Потемкина становится одновременно социальным творчеством, которому сопротивляются крестьяне деревни Макариха и старообрядцы скита. Преобразование географического пространства подразделяет всех на героев и антигероев. Авторы статьи приходят к выводу о том, что само по себе урбанизированное пространство не переделывает людей; изменение мировоззрения и воспитание личности возможны лишь посредством включения ее в соответствующую деятельность.

Ключевые слова: производственный роман, творчество Л. Леонова, «Соть», герои и антигерои.

D. V. Paul, A. A. Gaganova

\section{HEROES AND ANTI-HEROES IN THE PRODUCTION NOVEL (ON THE EXAMPLE OF THE NOVEL «THE SOT» BY L. LEONOV)}

\section{Moscow State Pedagogical University, Moscow, Russia}

\begin{abstract}
The article considers the system of characters in the novel «The Sot» by L. Leonov. The Soviet critics attributed this novel to the genre of «production novel». The authors analyze the system of characters, and put forward a hypothesis corresponding to the genre of production novel on the education of the human personality. The analysis of the text revealed that genre statements of the typical production novel are not implemented in «The Sot». Thus, the discussed novel expands the genre canon. The construction of a paper mill on the river Sot divided people into two warring camps, supporters and opponents of the industrialization of the peasant hinterland. The paper mill, the creator of which Ivan Uvadyev considers «a factory to serve the production of new people» in practice is not able to «educate» a person of a new type, but only conducts a rigid selection, sorting of people into carriers of the «industrial» and «peasant» mentality. The image of the future for Ivan Uvadyev and Sergey Potemkin becomes social creativity, which the residents of Makarikha and the old believers of the monastery resist. The transformation a geographical space divides the characters into heroes and anti-heroes. The authors conclude that the urbanized environment does not transform the people; a change in philosophy and education of the person is only possible through the inclusion into relevant activity.
\end{abstract}

Keywords: production novel, the works by L. Leonov, "The Sot», heroes and anti-heroes. 
Актуальность исследуемой проблемы. Актуальность исследования связана с необходимостью переосмысления советского периода русской литературы с целью поиска подлинных философско-эстетических смыслов в отрыве от типичной для этого исторического периода литературно-критической конъюнктурной оценки. Целью статьи является изучение художественной специфики образа героя особого жанра российской прозы - производственного романа.

Материал и методика исследований. Материалом для изучения послужили роман «Соть» Л. Леонова, а также академические и биографические исследования, посвященные произведениям и жизни писателя, диссертации и монографии, научные публикации и критические статьи в литературоведческих и публицистических журналах. В ходе работы над статьей применялись биографический, культурно-исторический, социологический, мифопоэтический, психологический, рецептивный методы.

Результаты исследований и их обсуждение. Роман «Соть» Л. Леонова демонстрирует психологические критерии героя и антигероя, которые ложатся в основу сюжетного конфликта. Доминантой литературного портрета является отношение героя к преобразованию действительности, а также его восприятие социальных и ценностных установок прошлого и нового времени.

Модель литературного конфликта «прошлое - будущее», с жестким противостоянием мировоззренческих ценностей, сформированная Л. Леоновым в «Соти», стала одновременно и типологическим признаком целого ряда довоенных производственных романов. Однако следует учесть, что жанровый канон производственного романа отличается социальным пафосом, романтизацией труда и мифологизированным образом героя. Согласно базовому постулату, содержательной основой подобного романа является тема труда, а объектом художественного изображения - человек труда, прежде всего индустриально-промышленного производства [4, с. 41]. Для канонического производственного романа как масштаб̆ного корпуса произведений, ориентированного на массового читателя, характерны четко расставленные акценты между героями и антигероями, так что у читателя не возникает сомнений в том, на пример каких персонажей следует ориентироваться. Канонический производственный роман (например, «емент» Ф. Гладкова) носит для читателя воспитательный характер, предельно упрощает литературный портрет героя и схематизирует конфликт между персонажами. Для автора канонического производственного романа значим не реальный социальный типаж, а «герой-идея» [4, с. 42].

На наш взгляд, «Соть» выходит за жанровые рамки производственного романа, обогащая это направление философской проблематикой. Жанровый канон создают произведения, которые можно объединить в относительно однородный и большой массив. Применительно к нашему исследованию можно констатировать, что для канонического производственного романа характерны социальный пафос, романтизация труда, воодушевляющая стилистика, схематизированные образы героев, «преодолевающие невозможное», а также типичный для целого ряда произведений сюжетный конфликт: «новатор - консерватор» или «советские люди - их внешний враг». К каноническим производственным романам мы относим, например, произведения Я. Ильина, В. Ильенкова, В. Кетлинской.

Тема труда, ставшая содержательной основой для российского производственного романа, в течение шести десятилетий привлекала внимание таких мастеров художественного слова, как Л. Леонов, А. Малышкин, Н. Ляшко, В. Катаев, И. Эренбург, Г. Николаева, В. Панова, Ю. Трифонов, В. Липатов, А. Бек, Д. Гранин и др. [4, с. 18]. Несмотря на более чем полувековое развитие этого жанра, самые яркие его образцы создавались за относительно небольшой отрезок времени: с середины 1920-х гг. до начала 1940-х гг. Именно этот период может считаться временем расцвета производственного романа, когда сформировались каноны жанра, появились наиболее интересные произведения. Ог- 
ромный вклад в его становление внесла проза Л. Леонова 1920-1930-х гг., которая не только продолжила художественно-эстетические искания русской литературы рубежа $\mathrm{XIX-XX} \mathrm{вв.,} \mathrm{но} \mathrm{и} \mathrm{открыла} \mathrm{новые} \mathrm{горизонты.} \mathrm{И} \mathrm{хотя} \mathrm{первым} \mathrm{каноническим} \mathrm{производст-}$ венным романом в русской (советской) литературе стал «Цемент» Ф. Гладкова, именно в «Соти» Л. Леонова оформились важнейшие принципы художественного изображения человека труда.

Действие романа Л. Леонова «Соть» (1929) происходит в лесном краю, на реке Соть, в Центральной России (Ярославская и Костромская области), которого почти не коснулась революция. В русской советской литературе «Соть» рассматривалась как классический производственный роман, и советские литературоведы любили подчеркивать высокую оценку этого произведения М. Горьким [6, с. 82]

Сюжетный конфликт разворачивается между людьми нового времени и старой эпохи. На берегу реки стоит монашеский скит, в котором живут озлобленные и боящиеся перемен, преимущественно «ряженые монахи» (беглые каторжники, преступники, спасающиеся от правосудия, белогвардейцы и другие противники Советской власти), враждебно встречающие известие о строительстве бумажного комбината.

Возможно, мотивация «ряженых монахов» к «уходу от мира» ради спасения жизни была особенно близка автору романа, непродолжительное время служившему в белогвардейской Северной армии, а потому он, по мнению 3. Прилепина, «всю жизнь боялся разоблачения» [12, с. 149]: «Леонов прожил целую жизнь, чувствуя затылком мрачное дыхание своего прошлого, которое в любое мгновение могло достигнуть и спихнуть его в небытие» $[12$, с. 150]. Впрочем, возможно и иное объяснение, связанное с повышенным вниманием писателя ко всему отличному от общепринятой нормы. «Тема отступничества (мировоззренческого перерождения человека) - одна из центральных у Леонова. Можно сказать, что писатель избрал проблему ущербности и непостоянства человеческого духа средоточием своей характерологии» $[5$, с. 220]. В любом случае, выбор героев был закономерен для Л. Леонова 1920-х гг.

Стройка на Соти превращается в поле битвы различных видений мира тех, кто обрашен в прошлое, с людьми, смотрящими в будущее. «При кратких промельках Луны корпуса лесов представали, как остовы огромных кораблей, на которых отважные моряки собирались отплыть в обетованные земли» $[8$, с. 160]. «Ломались рули, их заменяли новыми, только от мудрости капитана и выносливости самой команды зависел успех рейса туда, куда еще не заходили корабли вчерашнего человечества» [8, с. 161]. Эта метафора поставлена рядом с образом И. Увадьева, одного из наиболее ярких литературных портретов не только в творчестве Л. Леонова, но и производственного романа в целом. И. Увадьеву волею судьбы пришлось стать капитаном «корабля будущего». Именно его образ сращивается с темой перемен, произошедших на реке Соть. Финал романа рисует картину трагичной, но результативной реализации мечты: запорошенный снегом, сидящий на скамейке на вершине холма И. Увадьев любуется зажигающимися в ночи огнями Сотьстроя.

Персонажей «Соти» можно условно разделить на две группы: деятельные и бездеятельные. Первые - субъекты действия, обладающие собственным мышлением, вторые сами становятся объектами для воздействия со стороны других людей, в том числе лидеров социальных сообществ и профессиональных групп.

Подобная антитеза «люди действия - люди бездействия» художественно реализована в двух конфликтующих композиционных центрах романа [2, с. 111]: жители скита и «сотьстроители» (неологизм Л. Леонова). Работа над произведением начиналась именно с образа монашеского скита, отсюда и предположение о том, что автор задумывал «Соть» как роман о монахах $[1$, c. 25]. Однако в дальнейшем комбинат становится сюжетным центром, а скит - его оппозицией. 
Наиболее ярко антитеза деятельных и пассивных героев проявляется в литературной галерее мужских характеров. Женские образы, обладающие другой системой ценностей и потребностей, заслуживают отдельного разговора, а наиболее деятельные женщины, например, химик Сузанна, близки в образе мыслей к мужским литературным портретам. Образ Сузанны является одним из первых литературных портретов женщины-профессионала. К слову, несмотря на огромный массив произведений, посвященных теме труда, литературные портреты «женшины-профи» носят единичный характер. (Наиболее яркий пример образ Т. Карамыш из «Битвы в пути» Г. Николаевой.) Вообще, для жанра производственного романа проблематика женшины на производстве, обладавшая огромным художественным потенциалом, на наш взгляд, не была достаточно полно раскрыта $[4$, с. 230$]$.

Жители скита - коллективный образ более однородный, нежели тот, который складывается из строителей бумажного комбината. Важно отметить, что пассивноагрессивное отношение «монахов» к стройке как источнику неизбежных перемен совпадает с мировоззренческой позицией крестьян деревни Макариха; поэтому, говоря о «монахах», воображение невольно дорисовывает картину безграмотных, эгоистичных, «темных мужиков», пахарей, продолжаюших жить при свете лучины. Перед нами - «расширенное альтер-эго» старообрядцев, недаром И. Увадьев подозревает, что «скиток мог иметь крепкие корни в окрестных деревенских мужиках» [8, с. 32]. Получается двойной образ противников перемен: «ряженые монахи» и крестьяне. Среди жителей скита трудно отыскать хотя бы одного подлинного монаха-богослова с четкой теософской концепцией. Это отчетливо отражают диалоги между «монахами» и «сотьстроителями»:

Монахи всяко хвалили свое место <... $>$ «Бог - это все, что есть, а чего нет - тоже бог», - спокойно сказал молчавиий дотоле молодой монах. - «О несуществующем не может быть и мысли, - ульббчато метнулся Фаворов, соображая, про какого же батюику помянул игумен. - Ну, хорочо... ваш бог... имеет ли он вес, объем, величину?»«Нет». - «Что же он такое?» - «Бог!» - «Это Парменид, но только в русских смазанных сапогах! - громко сказал Сузанне Фаворов, а Увадьев, не подозревавиий в нем таких знаний, легонько подтолкнул его ногой, чтоб уж не сдавался [8, с. 21].

Опасение, что лесная чащоба и деревня Макариха станут мощным городским центром, а бумажный комбинат - градообразующим предприятием, является подлинной причиной ненависти «монахов» к разворачивающейся стройке. Бывший белогвардеец В. Булавин, работающий завклубом и научившийся мимикрировать ради приспособления к среде, пытается поднять крестьян на бунт против строителей бумажного комбината.

Ключевое различие между «ряжеными монахами» и крестьянами в том, что последние ищут пути наилучшей адаптации к условиям проживания в конкретных реалиях, в лесной чащобе, а «монахи», напротив, исповедуют философию эскапизма - бегства от реальности.

Жители деревни Макариха, как и обитатели скита, чувствующие себя «хозяевами территории», боятся перемен и потери привычного образа жизни. Само понятие перемен в образе жизни попадает и для крестьян, и для «монахов» в категорию табуированных. Заметим, что косность мышления крестьян, их недоверие и лживость, цинизм и жестокость перекликаются в «Соти» с более ранними произведениями Л. Леонова, прежде всего с романом «Барсуки» и «Необыкновенными рассказами о мужиках».

Консерватизм мышления жителей Макарихи коррелирует с другими произведениями Л. Леонова о деревне («Необыкновенные истории о мужиках»), отражающими «первобытное» мышление крестьян. Отупляющая косность характера безграмотного деревенского мужика - лейтмотив целого ряда сочинений Л. Леонова, и этот постулат справедлив для «Соти». Даже центральный дом Макарихи окружен атмосферой обветшания и упадка [8, с. 108]. 
Композиционным антагонистом центра бездеятельности является сюжетный центр активной деятельности, который персонифицирован в образах лидеров стройки: С. Потемкина, воплощающего лучшие традиции промышленников дореволюционной России, и организатора строительства И. Увадьева - советского партийного функционера:

Точно в огневой лихорадке, Потемкин зорко окинул собрание. Он даже сократил свое слово наполовину для придания ему деловитой крепости. Увадьев, к которому переило потом слово, не преминул подробнее остановиться на преимуцествах, на которые туманно намекал Потемкин. Кроме близости культурного очага, волость получала электрификацию, постоянную медицинскую помощь, иєколы фабзауча и непрерывную работу на предприятиях комбината этой столбовой дороги. Кроме того, по договору, который уже с месяи лежал в Губземуправлении, крестьяне получали готовую деревню в четырех верстах от нынеинего места, иколу и клуб, и, наконеч, среднюю стоимость урожая по данной полосе, рытье колодцев илл за счет переселяемых. $O_{н}$ закончил и, перечислив напоследок ряд лесных и налоговых льгот, неуклюже прокричал «ура» первому на Соти кирпичу сочиалистической кладки [8, с. 109].

Инициатор Сотьстроя, лесопромышленник С. Потемкин символизирует новое - активное преображение природы, смену прежних, устоявшихся веками отношений между человеком и окружающей средой. Фамилия главного героя - отсылка к Г. Потемкину, фавориту Екатерины II, кипучая деятельность которого преобразила все северное побережье Черного моря, и к одноименному броненосцу, увековеченному С. Эйзенштейном и ставшему одним из символов революции, то есть исторического действа, преобразующего прежний мир.

Для С. Потемкина лес на Соти - это прежде всего потенциальный экономический ресурс, который не работает, а лишь гниет и зарастает паутиной. «Именно пропадающее изобилие лесов и людей здешних, не вовлеченных никак в хозяйственный кругооборот страны, и надоумило Сергея Потемкина заказать знающим людям эскизный проект небольшого бумажного предприятия» $[8$, с. 50].

Деловитость - важнейшая характеристика С. Потемкина. Она же, по мнению отдельных исследователей, может быть отнесена и к самому Л. Леонову, в крайности даже утверждавших, что он очень деловой человек, с ярко выраженной предпринимательской жилкой, которому большевики не дали развернуться и стать предпринимателем, а в результате он стал писателем, примером «превращения художника в коммерсанта, в делового человека» $[5$, с. 106$]$.

С. Потемкин просчитывает разные экономические варианты, и первоначальная идея организации лесопилки перерастает в амбициозную идею создания бумажного комбината:

Ворчат! - Молвил Потемкин, угрюмо сворачивая на привычную тропу. - Лесу много, работы нет. На экспорт не берут, а в центр возить далеко. Доска не выдержит, а бумаге все впору. Мы вот решили, надо на месте лес работать! [8, с. 55].

С. Потемкин не только активный, энергичный человек, но и социальный лидер, у которого сложился образ будущего, преобразователь действительности, думающий об исторической перспективе. Он старается не адаптироваться к миру, как крестьяне Макарихи, не «скрыться от реального мира в религиозной иллюзии», как «ряженые монахи», а преобразовать действительность, что в психологии личности синонимично понятию творческого мышления. «Пробивной» и целеустремленный характер героя нацелен на преобразование болотистой «гнилой» местности в (ггород-сад) во имя будущих поколений, и в этом система ценностей социального лидера «по-Леонову» перекликается с экзистенциальным финалом «Фауста» И. Гете, особенно с финальной сценой поэтического романа.

Желание действовать с выходом на качественный результат - вот стратегия С. Потемкина, его страсть и одержимость. О проекте бумажного комбината, как о своем «де- 
тище», он думает днем и ночью, просчитывая его экономическую обоснованность и способы оптимизации ресурсов [8, с. 55].

Далеко не все знакомые героя обладают его энергией и желанием преобразовывать «пропадающий лес» в социально значимый промышленный объект. Многие игнорируют «дело Потемкина», угрожающее комфорту их формального отношения к делу, например, функционер Д. Жеглов, распределяющий банковские кредиты. Наконец, С. Потемкин встречает своего единомышленника - И. Увадьева.

Одержимость (устойчивая мотивация, когда все силы подчинены достижению одной сверхзадачи) как черта личности С. Потемкина и И. Увадьева вступает в конфликт с религиозным мировоззрением героев-антагонистов. Для обитателей скита, не имеющих мысленного образа будущего, и убежденных, что «на все воля божья», понятие одержимости относится к разряду ругательно-негативных. В мировоззренческих установках «ряженых монахов», сращенных с эскапизом и десоциализацией, интеллектуальная энергия и личностная активность, сила воли и масштабность человеческого характера интерпретируются как «проявление бесовщины».

Наряду с С. Потемкиным композиционный центр деятельности персонифицирован в образе И. Увадьева, который неожиданно для себя самого становится строителем бумажного комбината и даже возглавит стройку после того, как С. Потемкина сразит лейкемия. Обоих объединяют мысленный образ будущего, желание преобразовывать действительность, приближая ее к идеалу будущего. Образ И. Увадьева отражает идею создания общества будущего. Для него бумажный комбинат означает гораздо больше, чем для С. Потемкниа. Это и инструмент для создания человека будущего, и личная самореализация. Небывалая переделка географического пространства в его глазах обладает собственной эстетической ценностью - воображаемые девушки, которые будет носить шелк и ситец, производимый его комбинатом, носят имена Кати, Ани, Шуры. Для него эстетические категории связаны с человеческим обликом, а не с лесными пейзажами. Своими мечтами И. Увадьев делится с монахом Геласием:

Чудаковое слово - красота!. Вот мы встанем на этом месте, на берегу. Будем строить больиой завод. На том заводе станем мы делать иеллюлозу из простой ели, которой пропасть тут, без дела стоит. Из нее станут люди бумагу делать - для науки, пороха - чтоб отбиваться от врагов, и многое другое на потребу живым, а, между прочим, и шелк. <..> И будет она, Шура, скажем, или Аня, мой шелк на себе носить. И отсюда поведется красота! [8, с. 42].

И. Увадьев, и С. Потемкин - решительные люди, взгляды которых устремлены в будущее, они противостоят тем, кто, как жители скита, ментально обращены в прошлое. Мировоззренческий конфликт очевиден.

Заметим, что отношение литературоведов к персонажам «Соти» резко менялось, отражая действующую идеологию. Если в советские годы положительными героями «Соти» были строители И. Увадьев, С. Потемкин, Бураго [7, с. 97], то в 90-е гг. XX в., в период либерализации российской экономики, в «Соти» обнаружили новые смыслы. Теперь образ бумажного комбината сравнивали с метафорой котлована у А. Платонова» [2], преобразование лесного захолустья трактовали как разрушительное вторжение человека в гармонию леса [11], а в гибели ребенка от удара бревном, вырванным рекой, усматривали сакральную жертву. В основе стройки - трагедия [2], река и природа сопротивляются приходу людей, а значит, и сам Л. Леонов не разделяет идеи социалистической стройки [11]. Проводя аналогию с «Котлованом» А. Платонова, Т. Вахитова приходит к выводу о том, что Л. Леонов не одобряет идею социалистической стройки, ведь в случайной гибели одиннадцатилетнего ребенка, играющего возле реки, персонаж рома- 
на И. Увадьев усматривает аллюзию на «девочку Катю», которая символизирует в его воображении будущее [3, с. 122].

Исследователи Т. Вахитова и В. Петищева в отдельный элемент сюжетного конфликта выносят «образ реки Соти». Для них он самостоятелен, недаром в финальной фразе романа меняется «Лик Соти», возникает аллюзия на Святую Женщину. Аргументируя свою точку зрения, В. Петищева, например, пишет:

В структуре книги важсню художественную роль играет река Соть - одухотворенный поэтический образ и символ, противостоящий дисгармоничному миру людей. В романе получил новое развитие мотив «покорения» природы, сориентированный на «индустриальный миф», и впервые обозначился неразрешимый конфликт между природой и человеком, преобразующим географию края [10, с. 23].

Возвышая сюжетную роль образа реки, В. Петищева сравнивает Л. Леонова с М. Пришвиным:

Эстетические и философские взгляды. Леонова во многом тождественны взглядам Приивина, создателя «новой мифологии», отличной от официальной, с ее приматом коллектива над личностью [10, с. 30].

Однако, на наш взгляд, данная точка зрения не вполне правомерна. У М. Пришвина природа выполняет ведущую символическую и метафорическую функцию, обобщая человеческие чувства, в то время как у Л. Леонова сюжетный конфликт «Соти» строится на конфликте между людьми разных эмпирических и идеологических установок.

Неслучайно сегодня ученые возвращаются к традиционной точке зрения на этот роман, усматривая в ответном ударе реки констатацию факта высокой платы за преобразование мира и утверждая, что «сотьстроители» остаются настоящими героями, альтруистами, фанатиками, вершителями невозможного, целеустремленности которых ничто не в силах помешать [9, с. 92].

Именно И. Увадьеву как социальному лидеру своего времени (НЭПа) Л. Леонов посвящает финальную сцену романа. Преобразователь действительности, с нечеловеческой волей и мужественностью достигший цели, он восходит на вершину холма и замирает, покрывается снегом, словно бы становится памятником, символом эпохи; «... менялся лик Соти, и люди на ней переменились» $[8$, с. 288] - хрестоматийно известная строчка, подводящая логическую черту произведения о переделке мира и преобразовании российской действительности.

Таким образом, композиционный центр романа «Соть» Л. Леонова определяется антагонизмом деятельностных и бездеятельных персонажей. Глубинная мотивация поведения последних проявляется либо в таких поведенческих стратегиях, как эскапизм и десоциализация («ряженые монахи»), либо в адаптации к среде, то есть ведении натурального хозяйства (деревенские крестьяне). Деятельностные персонажи отличаются поведенческой стратегией не адаптации, а преобразования среды ради общества будущего, что может рассматриваться как социальное творчество. С. Потемкин символизирует лидера, сосредоточившего свою энергию вокруг экономического преобразования болотистого и лесного захолустья. И. Увадьев обладает поэтическим образом будущего, его социальное лидерство связано с эстетическим представлением о будущем, о преобразовании леса, заросшего паутиной и сухостоем, в «город-сад».

Антагонизм персонажей отражает их отношение к людям. Эгоизму «ряженых монахов», живущих в ограниченном маленьком мире и обеспокоенных прежде всего благосостоянием своих ветхих изб и личных земельных наделов, противостоят альтруистические установки социальных лидеров С. Потемкина, И. Увадьева, инженера Бураго, химика Сузанны и других «сотьстроителей», пришедших в лесное захолустье из большого миpa, затронутого индустриализацией, и глобально задумывающихся о качестве жизни бу- 
дущих поколений. Понимая важность образования безграмотных, «дремучих» крестьян, они фанатично, в четыре смены возводят комбинат, символом продукции которого становится букварь для деревенской девочки Кати.

Мы видим, что художественное пространство стройки не преображает и не воспитывает человека, что было бы характерно для канонического производственного романа с его лейтмотивом воспитания и перевоспитания личности, а сортирует, группирует людей в разные мировоззренческие микросоциумы. Эти микрогруппы способны становиться непримиримыми враждующими лагерями. Приход большого мира, несущего революционные перемены индустриализации в маленький мир провинции, сопровождается сопротивлением защитников привычного уклада жизни. Персонажи оказываются поделены на сторонников и противников строительства, и те, кто противостоит стройке, выбрасываются за пространство этого топоса, символизирующего новый мир и новое время. Таким образом, мы видим, что «Соть» не является каноническим производственным романом, а скорее философским произведением, расширяющим художественный канон направления российской прозы о человеке труда.

Резюме. Мы гипотетически предположили, что преобразованная руками человека географическая местность, литературный топос как новое пространство способны создавать человека нового типа. Подобным пространством становится урбанизованный берег реки Соть. Однако последовательно пройдя весь путь авторской логики вместе с персонажами, мы пришли к выводу, что сам по себе новый топос не формирует и не воспитывает нового человека. Комбинат распределяет персонажей в два лагеря - сторонников прошлого и нового времени. Реальное изменение мировоззрения и воспитание личности оказываются возможны лишь посредством включения человека в соответствующую деятельность.

\section{ЛИТЕРАТУРА}

1. Вахитова Т. М. Леонид Леонов: жизнь и творчество. - М. : Просвещение, 1984. - 128 с.

2. Вахитова Т. М. Леонов и Платонов. «Соть» и «Котлован» //. Вахитова Т. М. Художественная картина мира в прозе Леонида Леонова (структура, поэтика, эволюция). - СПб. : Наука, 2007. - С. 109-122.

3. Вахитова Т. М. Художественная картина мира в прозе Леонида Леонова. - СПб. : Наука, 2007. - 317 с

4. Гаганова A. A. Производственшый роман: кристаллизация жанра. - М. : Спутник+, 2015. - 244 с.

5. Дырдин А. А. Проза Леонида Леонова: метафизика мысли. - М. : Синергия, 2012. - 294 с.

6. История русской советской литературы. - М. : Высшая школа, 1970. $-696 \mathrm{c}$.

7. Ковалев В. А. Этюды о Леониде Леонове. - М. : Современник, 1978. - 326 с

8. Леонов Л. М. Собрание сочинений : в 9 т. Т 4. - Л. : Гослитиздат, 1961. - 352 с.

9. Мухаммед Р. М., Макарем Э. Г. Борьба нового со старым в романе Л. Леонова «Соть» //. Молодой ученьй. - 2018. - № 37. - С. 89-95.

10. Петищева В. А. Романы Л. М. Леонова 1920-1990-х годов: эволюция, поэтика, структура жанра : автореф. дис. ... д-ра филол. наук : 10.01.01. -Бирск ; М., 2007. - 39 с.

11. Петииева В. А. Романы Л. Леонова 20-30-х годов в вузовском изучении : учебное пособие для студентов. - Бирск : Башкортостан, 2004. - $167 \mathrm{c}$.

12. Прилепин 3. Н. Леонид Леонов. - М. : Молодая гвардия, 2010. - 608 с

Статья поступила в редакцию 11.10.2019

\section{REFERENCES}

1. Vahitova T. M. Leonid Leonov: zhizn' i tvorchestvo. - M. : Prosveshchenie, 1984. - 128 s.

2. Vahitova T. M. Leonov i Platonov. «Sot'» $\mathrm{i}$ «Kotlovan» // Vahitova T. M. Hudozhestvennaya kartina mira v proze Leonida Leonova (struktura, poetika, evolyuciya). - SPb. : Nauka, 2007. - S. 109-122.

3. Vahitova T. M. Hudozhestvennaya kartina mira v proze Leonida Leonova. - SPb. : Nauka, 2007. $-317 \mathrm{~s}$.

4. Gaganova A. A. Proizvodstvennyj roman: kristallizaciya zhanra. - M. : Sputnik+, 2015. - 244 s.

5. Dyrdin A. A. Proza Leonida Leonova: metafizika mysli. - M. : Sinergiya, 2012. - 294 s. 
6. Istoriya russkoj sovetskoj literatury. - M. : Vysshaya shkola, 1970. - $696 \mathrm{~s}$.

7. Kovalev V. A. Etyudy o Leonide Leonove. - M. : Sovremennik, 1978. $-326 \mathrm{~s}$

8. Leonov L. M. Sobranie sochinenij : v 9 t. T 4. - L. : Goslitizdat, 1961. - $352 \mathrm{~s}$.

9. Muhammed R. M., Makarem E. G. Bor'ba novogo so starym v romane L. Leonova "Sot'»// Molodoj uchenyj. - 2018. - № 37. - S. 89-95.

10. Petishcheva V. A. Romany L. M. Leonova 1920-1990-h godov: evolyuciya, poetika, struktura zhanra avtoref. dis. ... d-ra filol. nauk : 10.01.01. - Birsk; M., 2007. - $39 \mathrm{~s}$.

11. Petisheva V. A. Romany L. Leonova 20-30-h godov v vuzovskom izuchenii : uchebnoe posobie dlya studentov. - Birsk : Bashkortostan, 2004. $-167 \mathrm{~s}$.

12. Prilepin Z. N. Leonid Leonov. - M. : Molodaya gvardiya, 2010. - $608 \mathrm{~s}$.

The article was contributed on October 11,2019

\section{Сведения об́ авторах}

Поль Дмитрий Владимирович - доктор филологических наук, профессор кафедры русской литературы XX-XXI веков Института филологии Московского педагогического государственного университета, г. Москва, Россия; e-mail: pol-d-v@yandex.ru

Гаганова Анна Анатольевна - стажер кафедры русской литературы XX-XXI веков Института филологии Московского педагогического государственного университета, г. Москва, Россия; e-mail: briolett $a$ yandex.ru

\section{Author information}

Paul, Dmitry Vladimirovich - Doctor of Philology, Professor of the Department of Russian Literature of the 20th-21st Centuries, Institute of Philology, Moscow Pedagogical State University, Moscow, Russia; e-mail: pol-d-v@yandex.ru

Gaganova, Anna Anatolyevna - Trainee of the Department of the Russian Literature of the 20th-21st Centuries, Institute of Philology, Moscow State Pedagogical University, Moscow, Russia; e-mail: briolett $a$ yandex.ru 